\title{
Exploring Outdoor Play in Kindergartens: A Literature Review of Practice in Modern Greece
}

\author{
Aglaia Zafeiroudi (Corresponding author) \\ Department of Physical Education and Sport Science \\ University of Thessaly, Karies, Trikala, 42100, Greece \\ Tel.: 30-243-104-7004Ｅ-mail: aglaiazaf@hotmail.com
}

Received: May 13, 2021

Accepted: July 10, $2021 \quad$ Published: August 1, 2021

doi:10.5296/jse.v11i3.18724

URL: https://doi.org/10.5296/jse.v11i3.18724

\begin{abstract}
This study investigated current research on education in Greek kindergartens and the integration of outdoor activities into kindergarten programmes. A literature review was conducted using ERIC, JSTOR, SpringerLink, Education Research Complete, Scopus, Google Scholar, and EBSCO-host electronic databases for the years 2017-2021. The review revealed that participation in outdoor play and activities in early childhood remains very low despite the multiple benefits to children of all ages. Multiple barriers to outdoor activities exist, including poor outdoor play facilities and equipment, the negative perceptions of parents and teachers, and a lack of support from the Greek educational system. This study attempts to initiate a discussion about the inclusion of outdoor play in kindergarten curricula as a move towards a more outdoor approach to early childhood education in Greece. A number of changes are proposed to fill the gaps that kindergarten children benefit from their early involvement in activities outside the classroom. Outdoor play in Greek kindergartens could be a continuation of indoor education, supporting children to live healthier physical, emotional, psychological and spiritual lives.
\end{abstract}

Keywords: outside lifestyle, preschools, outdoor activities, motor skills, nature, environmental sustainability, early childhood. 


\section{Introduction}

Play benefits children in many aspects of life supporting fitness, emotional and physical health, creativity, and social skills (Guirguis, 2018; O'Neill, Rajendran, \& Halperin, 2012; Little \& Wyver, 2008; Ashiabi, 2007; Manwaring \& Taylor, 2006; Barnett, 1990). According to Bento and Dias (2017), play is a compelling and natural activity that promotes social, physical, cognitive and emotional wellbeing. It helps children to learn and thrive by providing a platform to experiment, think creatively, solve problems and cooperate with others (Bento \& Dias, 2017). The same researchers supported that the associations that emerge from play help children to gain deeper self-awareness and deeper knowledge of the world around them. Furthermore, providing children with opportunities for unstructured outdoor play allows them to decide what to do and who to do it with, thus promoting confidence, autonomy and self-esteem. According to Flannigan and Dietze (2017), play is an act that is intrinsically motivating, meaningful, symbolic, freely chosen, opportunistic, actively engaging and pleasurable. Sando and Sandseter (2020) define play from the perspective of the child as self-controlled, voluntary, unlimited, natural, free and fun.

\subsection{Objectives of the Study}

This study is an attempt to initiate a discussion about the need to include outdoor play in kindergarten curricula as a move towards a more outdoor approach to early childhood education in Greece. This paper examines current research related to outdoor play in Greek kindergartens, with an emphasis on identifying some of the activities that constitute outdoor play and the benefits of participation, in order to discuss problems, gaps in knowledge and make recommendations for the future.

\section{Methods}

A literature review was conducted using ERIC, JSTOR, SpringerLink, Education Research Complete, Scopus, Google Scholar, and EBSCO-host electronic databases. Various combinations of keywords were used to search these databases: preschool children, kindergarten, outdoor play, outdoor activities, motor skill development, physical activity, cognitive development and social interaction. The search was limited to articles written in English and published between 2017 and 2021. Secondary references were selected from the bibliographies of the primary literature. Furthermore, government websites, such as the Ministry of Education and Religious Affairs and the Ministry of Culture and Sport Greece, were examined for pertinent publications and reports.

\section{Findings}

\subsection{The Contribution of Outdoor School Play in the Early Years}

As children navigate natural elements during outdoor play, they are exposed to challenges and risks (Zafeiroudi, 2020). Outdoor environments encourage children to explore nature with curiosity as they seek to find out more about what they encounter. It would appear that outdoor activities are crucial for the development of children and they offer numerous benefits. 


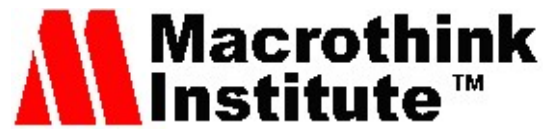

Journal of Studies in Education

ISSN 2162-6952

2021, Vol. 11, No. 3

According to Abd Rahim et al. (2020), children benefit from an early childhood education facilitated by an organized and planned curriculum that allows for experimental learning. There are numerous benefits to engaging in outdoor activities, including emotional, life skills development, learning and environmental sustainability. As Hargraves (n.d.) notes, being in nature and learning out of doors are crucial childhood experiences that support development and education. Therefore, this section highlights the benefits to children of participation in outdoor activities and the association between acquired motor skills and emotional knowledge with life development skills and environmental sustainability.

According to Zafeiroudi (2020), the outdoor environment is crucial for children as it offers unique stimuli that attract the interests and attention of participants. The natural environment offers countless opportunities for children to explore soil, flowers, water, rocks, sticks and other objects and materials with enthusiasm and curiosity. Bento and Dias (2017) suggest that objects found in nature can be categorized as open-ended materials with the potential to respond to the needs and imaginations of children. For example, when children assign new meanings to objects and engage in processes of reinvention, they mobilize such skills as divergent thinking, problem solving and creativity.

Zafeiroudi (2020) argue that the exploration of nature, through outdoor activities, captures the attention of young children and feelings of fascination and discovery facilitate emotional connections with the environment. Children's exposure to nature also promotes their understanding of the value of nature to human life. Unstructured play in natural environments, therefore, increases familiarity with nature and creates a sense of belonging at an early age that encourages lifelong sustainable and ecological behaviours (Bento \& Dias, 2017).

A further benefit of participating in outdoor play is the promotion of education in its widest sense. Activities that involve playing with soil and water are perfect examples of materials that provide learning opportunities in areas such as science, mathematics and language (Bento \& Dias, 2017). For example, when children engage in emptying and filling containers, they begin to explore mathematical and physical concepts related to volume, time and weight. At the same time, they develop language skills as they express themselves using new vocabulary they acquire in the course of their adventures. Bento and Dias (2017) note that, when engaged in outdoor play, children use their bodies as learning tools as they employ mathematical procedures to their play.

Outdoor activities that involve interactions with nature are beneficial to children's health. For example, playing with soil helps to build immunity. Exposure to the environment has been found to reduce the aggravated symptoms of children who suffer from skin and respiratory problems, such as eczema and asthma (Bento and Dias, 2017). Furthermore, Sando (2019) claims that contact with green open spaces has a positive restorative effect on children's stress levels, while Rodriguez-Ayllon et al. (2019) posit that physical health supports the mental health of both children and adolescents.

According to Pomohaci and Sopa (2017), schoolmates and friends provide a platform for socialization at an early stage of life. Researchers argue that the atmosphere established outside the classroom and when engaged in outdoor activities provides a suitable 
environment for children and adults to showcase their diverse personalities (Zafeiroudi, 2020; Zafeiroudi, 2014; Zafeiroudi \& Hatzigeorgiadis, 2014; Garitsis et al., 2010). Outdoor play provides the opportunity for adults to better understand children, thus facilitating appropriate educational interventions. Bento and Dias (2017) also point out that fewer conflicts take place during outdoor play. This suggests that children can more successfully cooperate when engaged in outdoor activities, thus contributing to the creation of common goals, and resulting in companionship among peers.

Children in preschool and kindergarten benefit from knowledge shared when engaged in outdoor activities. During outside play, children become learners and tutors, sharing their skills and knowledge as they accomplish different challenges and tasks. Bento and Dias (2017) suggest that this process of cooperation has the potential to develop empathy, as children learn to understand the needs and feelings of others. One outstanding feature of interactions in the outdoor environment is that they happen gradually. This allows young children to select those moments with which they want to associate and those individuals with whom they want to connect. Outdoor spaces address the issue of children not having to continually run into others with whom they do not want to play.

According to Wray et al. (2020), improving socialization and physical activities can be achieved through the incorporation of play-focused and natural elements into outdoor spaces. The outdoor environment provides a platform where kindergarten children can interact with adults in an atmosphere that is more open to flexibility and dynamic engagement. During outdoor play, adults appreciate the environment and are available to offer children the support they need in their endeavours. Outdoor environments provide a calm and relaxed atmosphere that enhances interactions between adults and children. In addition to the benefits that children gain from outdoor play, outdoor environments reduce adult anxiety and stress levels. Various models describe the relationship between adults and children during outdoor play. However, Bento and Dias (2017) caution that outdoor play should be flexible, child-led and based on ideas that revolve around the interests and discoveries of the child.

When participating in outdoor play, children are exposed to different aspects of risk. This helps them to learn to anticipate and manage risk. According to Bento and Dias (2017), contemporary society does not value the importance of risk in childhood development and learning. Embracing a culture of fear is counterproductive, as it leads to the underestimation of children's potential and abilities. As a result, adults may design learning environments that do not promote the acquisition of experiential knowledge about staying safe. Adults in kindergartens settings must adopt a broader vision of risk that extends beyond the possibility of accidents. In this way, they will ensure that they will also consider the positive outcomes associated with feelings of success and achievement when a child learns a new skill. Therefore, adults play a key role in exposing children to the realities of life to enable them to understand and start developing a mindset that considers all aspects of life.

The outdoor environment provides children with the opportunity to grow and develop through play. For example, Bento and Dias (2017) point out that outdoor environments provide opportunities to exceed personal limits, such as, for example, attempting to climb 
trees or utilize tools. Such opportunities cannot be accessed in indoor learning environments. Adults can support kindergarten-aged children in risky play. This allows them to observe the children and appropriately interpret how they should behave. For example, certain signs may reveal that a child requires space to perform actions or activities with greater ease. Signs may also reveal that the child needs support to accomplish a specific task. Therefore, using attentiveness and discretion, adults can help children through risky play by being present to offer whatever support is necessary. Bento and Dias (2017) emphasize that risky play promotes crucial skills associated with problem-solving, self-knowledge, entrepreneurship and persistence.

It is important that children learn that there are both successes and failures in life. Outdoor learning provides a platform to experience life's victories and downfalls. When engaged in outdoor activities, children are exposed to materials and experiences that they will not have interacted with before. Such engagements, therefore, take place through trial and error as children have opportunities to understand the workings of outdoor facilities and equipment. Through trial and error, children may succeed in some of their interactions and fail in others. Bento and Dias (2017) argue that attempting to prevent all risky situations denies children the opportunity to learn to deal with unpredictable environments. This may result in children lacking the confidence to autonomously overcome challenges.

Other activities, such as museum visits, have a positive impact on children's learning processes. According to Davidson (2018), museums equip children with the knowledge to establish connections between museum displays and history. This opposes a more traditional classroom approach in which children are taught about historical events and figures of historical importance. According to Davidson (2018), field trips to places such as museums can enhance formal education, helping children to acquire knowledge, skills and values that can be applied in that subject and throughout life. Furthermore, such trips allow children to compare and contrast information and exhibits as they analyse and pinpoint those aspects that they consider important based on their level of understanding. Engagement that allows kindergarten children to compare and contrast different perspectives contributes to the development of critical thinking skills.

The motor skills that children gain from outdoor play are critical for their growth and development. Motor competence is conceptualized as the level of performance of an individual when executing both gross and fine motor tasks (Haga et al. 2018). An individual is a dynamic system in which changes in motor behaviour occur over time based on the activities in which one is engaged. Palmer et al. (2019) argue that motor interventions can help to enhance individual motor skills. Haga et al. (2018) assert that motor development is a continuous process of change in movement and interaction, driven by the individual, the task and the environment. This suggest that, although the development of motor competence is dependent on maturity and growth, other factors, such as environmental context, play an essential role in developing motor proficiency. Therefore, providing children with opportunities to engage in motor activities benefits them in a variety of ways, including their health. 


\section{MInstitute ${ }_{\text {Mnk }}^{\text {Macrothink }}$}

Journal of Studies in Education

ISSN 2162-6952

2021, Vol. 11, No. 3

Slining et al. (2021) assert that obesity in childhood is associated with long-term health risks. Therefore, poor motor competence is categorized as a noticeable weakening in the performance of motor skills. This is counterproductive to childhood development, as poor motor competence has a significant long-term impact on behavioural, social and emotional development. Therefore, for kindergarten children, motor competence is an important contributor to health and wellbeing. Engaging in outdoor play is crucial in brain development. Recent neuroscience research has established that play impacts the proper functioning and development of children's brains (Loebach \& Cox, 2020). During play, the brain engages in testing and simulation, implying that the brain is trying to make sense of itself (Loebach \& Cox, 2020). Since childhood is the period in life when the most significant brain development occurs, it is imperative that outdoor activities are incorporated into the kindergarten curriculum. Loebach and Cox (2020) further note that during play, all parts of a child's brain light up, resulting in prosocial and adaptive alterations at cellular, molecular and behavioural levels. This reinforces the argument that play activities simultaneously foster learning and development across cognitive, physical, emotional and social domains. One important way to facilitate brain development, therefore, is to engage children in outdoor play rather than restricting them to indoor environments and activities.

\subsection{Kindergarten Education in Greece}

Outdoor activities are practices that take place outside the classroom. These include activities such as tours of forests and parks, field trips to theatres, art centres and museums. Meanwhile, indoor environments include human-made settings where people work, reside or spend time (Saridi et al., 2021). The Greek government recently introduced regulations on the operation of institutions such as toddler, preschool and infant day-care centres (Kalpogianni, 2019) to ensure that educational programmes are child-centred and respect children's cultural, social and personal differences. Kalpogianni (2019) classifies Greek preschool services into day-care centres and kindergartens. The latter fall under the remit of the Ministry of Education and educate children aged 4-6 years, while day-care centres are for children aged between 6 months and 5 years and are the responsibility of the Ministry of the Interior. An important difference between the two preschool settings is that kindergartens follow the national curriculum while day-care centres rely on regulations related to operational issues only.

However, despite the significance of outdoor play in early childhood, the Greek government does not provide sufficient guidance in this area (Kalpogianni, 2019). For instance, day-care centre regulations in effect from 2002 to 2017 did not directly mention the outdoor environment (Kalpogianni, 2019). Instead, the regulations referred only to outdoor time, such as that daily recess time should be approximately 30 minutes. Policies emphasize the length of time to be spent outdoors, with suggestions that age and the personal and psychological needs of children should determine the time allocated for outdoor play. No reference is made to use of the outdoor environment.

Some of the outdoor activities that children engage in include playing with blocks, using fine motor skills and creating art. Kalpogianni (2019) argues that a focus on activities such as 
these is at the expense of adventures related to science and nature. Despite a lack of data on the length of time that Greek preschool children spend outdoors, there is evidence that sensory and physical play is not sufficiently promoted. Hargraves (n.d.) argues that the development of policies and philosophies within early childhood schools and settings has a significant impact on children's outdoor activities. This suggests that there is a lack of proper regulation regarding outdoor, physical and motor activities and kinetic group play, in addition to a lack of information and teaching, for both children and parents, of the lifelong benefits of exercise. These are clear gaps in currents kindergarten policies in Greece (Venetsanou et al., 2019; Venetsanou \& Kambas, 2017; Doliopoulou \& Rizou, 2012).

Sakellariou and Banou (2020) point out some of the practices that educators currently use to encourage more outdoor activities among children in Greece. Among these are the use of raw materials in play, which demonstrates educators' knowledge of the significance of such materials in children's developmental and learning processes. Kindergarten educators encourage children to engage in the design of play settings in outdoor environments. However, Sakellariou and Banou (2020) point out that the design of kindergartens in Greece is based on adult perspectives, thus failing to cater to the needs of children. Regardless, educators play a role in the evaluation of play equipment and other objects available in the schoolyard. Educators believe that evaluating play settings allows for the replacement of inferior materials with high-quality materials that appeal to and benefit children (Sakellariou \& Banou, 2020).

Hargraves (n.d.) highlights certain policy areas that can enhance outside activities. These include kindergarten and preschool values related to outdoor play and their commitment to use outdoor spaces, and principles for practice that include uninterrupted play sessions, child-led activities and free movement between outdoor and indoor settings. In addition, outdoor environments should be supervised by an individual who can perform such duties as managing risk and guiding the involvement of families and communities in outdoor activities. Therefore, a comprehensive policy that captures multiple aspects of outdoor activities enhances the involvement of children in practices and adventures outside the classroom.

Historically and at present, Greek curricula lack engagement in motor activities (Venetsanou $\&$ Kambas, 2017). In addition, there is no active role for outdoor play in the country's formal education system (Sakellariou \& Banou, 2020). Outdoor play is closely related to kinetic skills, abilities and neural development. The lack of motor development is associated with learning difficulties and behavioural, pedagogical and social problems (Zaragas \& Pliogou, 2020). In Greece, approximately $23 \%$ of preschool aged children are categorized as overweight or obese (Venetsanou \& Kambas, 2017). Obesity is linked with a number of chronic diseases, and with stress, anxiety and depression in later phases of childhood (Zaragas \& Pliogou, 2020).

Gregoriadis et al. (2016) report that Greek kindergartens and day-care settings do not focus on activities related to nature and that schoolyards are usually not equipped with natural materials, such as water and sand. The national kindergarten curriculum includes no guidelines for diverse activities and outdoor equipment. The same researchers found that 
parents are reluctant for their children to be exposed to the elements, or to get dirty or wet, and often complain when this occurs. Greek parents have also reported that the main barriers to their children playing outdoors are poor facilities, lack of places to play, lack of availability and poor quality of play spaces and the weather (Sandseter et al., 2020). The independent mobility of Greek children is also among the lowest in the Europe, which is also a factor in reducing opportunities for outdoor play. Greece also appears to have a higher accident rate than other European countries. Parents restrict both their children's freedom of movement outdoors and freedom to participate in outdoor activities. Finally, compared to countries such as Norway and Sweden, outdoor activities are not emphasized in Greek kindergartens and no legislation exists to promote such activities (Haga et all, 2018).

\subsection{Major Barriers, Problems and Gaps}

This paper reveals a number of themes relating to outdoor activities in Greek kindergartens. Little has changed in the Greek kindergarten education system with regard to playing in nature and outdoor activities. Outdoor play continues to be associated with challenges, obstacles and gaps, which, if addressed, could enhance outside play and learning for kindergarten children. This section explores several issues that have emerged from a review of how outdoor activities are carried out in Greece.

According to Kalpogianni (2019), Greek children are allocated limited time for outdoor pay. Day-care centres lack clear policies regarding the productive use of outside environments. This lack of proper guidelines highlights that lack of emphasis placed on outside activities. In addition, the use of outdoor space is a concern that has yet to be addressed. Kalpogianni (2019) notes that some educators consider outdoor play a break from the educational and child-care activities of the day-care centre. This perspective may render outdoor environments as suitable recess spaces rather than places where children can develop and learn.

The needs of children are not currently fully met during outdoor play. One benefit of outdoor physical activities is that they improve children's health. According to Kokolaki et al. (2018), making physical activity part of one's daily routine from early childhood is vital for lifelong health. However, the outdoor environment in Greece does not seem to meet the health needs of the country's children. Hu et al. (2020) point out that most poor health conditions in preschool children result from unhealthy lifestyles. Kalpogianni (2019) points out that recent obesity prevention guidelines propose that for every hour a child spends in day-care, 15 minutes should be dedicated to physical activity. Therefore, the limited time spent outdoors does not meet the health needs of children who spend up to eight hours per day in Greek day-care centres. Despite the use of outside kindergarten spaces, there is a lack of emphasis on the value of outdoor play, such as in the prevention of obesity.

Educators play an important role in supporting children's outdoor activities. According to Kalpogianni (2019), the presence of teachers during outdoor play is essential in supporting children in their developing understanding of the dynamics of nature, such as risks and opportunities. Educators can provide a supportive environment in which children can develop communication skills, imagination, cooperation, flexibility and different perspectives. 


\section{Mll Macrothink}

Journal of Studies in Education

ISSN 2162-6952

2021, Vol. 11, No. 3

Tuuling et al. (2019) found that some educators associate outside learning with joy, independence and freedom. How educators perceive outdoor play influences the framework within which they work to inspire children's interactions with and in the outdoor environment. Clarity is required regarding the roles, skills and competencies of adults. Furthermore, educators should be aware of the significance of space and timing in the attainment of adventure experience goals.

Some participants in Kalpogianni's (2019) research considered the role of the adult in outside spaces to be that of facilitator, while others saw the role as that of observer. Educators assuming the role of observers, however, may lack a clear plan to observe and support the needs of the children in their care. Furthermore, observers may simply supervise without documenting the children's actions or making observations regarding improvements that can be made to the outside environment to better cater to the children's learning and developmental needs. The responses of participants in that research demonstrate a difference in the perceptions of kindergarten educators. With some perceiving their role to be that of observer and others that of facilitator, it is clear that comprehensive standardized guidelines are required to give educators direction regarding their role in outdoor play.

Similarly, Erdem (2018) found that preschool educators have different opinions and practices regarding their mandate. While some teachers acknowledge the role of outdoor activities in childhood development, they do not embrace such activities for reasons such as safety risks, injuries and weather conditions. As a result, these educators prefer indoor play with ropes and balls. However, this practice is contrary to the requirement that children have the opportunity to spend some time outdoors each day.

The setting for outdoor activities is crucial, as the environment determines the natural elements that children will encounter. According to Kalpogianni (2019), the physical structure of Greek day-care centres demonstrates a lack of emphasis on outdoor practices. The regulatory standards that guide the licensing of day-care centres require a semi-outdoor or outdoor space of 4.5 square meters per preschool child and 3.5 square meters per infant. However, 7.5 percent of educators in Kalpogianni's (2019) study worked in day-cares that lacked space for outdoor activities and day-care centres were found to have inadequate outdoor space of less than 100 square meters, which does not meet the established requirements for preschool settings. Moreover, among the participants of Kalpogianni's study, 6.9 percent indicated that children do not participate in outside activities at all. This implies that, in situations where there is no outdoor space, alternative arrangements are not in place to ensure that children have opportunities to play outside. Therefore, without a proper physical structure that encourages activities outside the classroom, incorporating meaningful outdoor activities that promote development and learning can be difficult.

Educators are increasingly interested in place-based education (Perlman et al., 2020). Before addressing the nature of outdoor spaces, preschool centres should ensure the preservation of areas for adventure and outside activities. The size and quality of outdoor spaces matter, as appropriate environments enhance learning abilities and childhood development (Kalpogianni, 2019). Indoor environments in Greece's public day-care centres are often of low quality and 
do not encourage play (Kalpogianni, 2019). Therefore, outside play environments should be configured in ways that provide children with opportunities to interact with nature.

Interactions between children in outdoor spaces may face certain challenges, such as aggressive behaviour. According to Kalpogianni (2019), day-care centre educators have to deal with conflict between children during play time. Educators are also concerned about the ways that children respond to conflict. For instance, when conflict arises during play, children are unable to resolve their differences (Kalpogianni, 2019). This can be attributed to children's lack of understanding of how best to deal with new situations. However, educators are concerned that poor-quality educational environments fuel conflict. For example, the arrangement and characteristics of the physical environment and the materials available affect how children behave and the type of games they can play. This suggests that children's playful nature can be enhanced or restricted by the resources to which they are exposed. Therefore, Kalpogianni (2019) argues that limited outdoor environments have a negative impact on children's behaviour.

Preschool educators face numerous challenges as they attempt to balance the work they have to do with the support they receive from institutions. According to Erdem (2018), among the issues that make it difficult for educators to facilitate outside education are unsuitable physical spaces and the failure of administrators to offer the support needed to engage in outdoor activities. As a result, without the support of other stakeholders, teachers are unable to implement what they believe are the best approaches to enhance children's development and learning.

Another obstacle that teacher's face is the attitude of parents to outdoor play. Erdem (2018) found that parents' attitudes towards outdoor activities are exclusively negative. Parents associate outside play with negative consequences such as sickness and risk. Given parents' negative attitudes, educators minimize the intensity with which they lobby for activities outside the classroom. Safety is the biggest concern for parents. In an effort to avoid injury to their children, they are more likely to support indoor play.

According to Erdem (2018), schoolyards with poorly designed physical space hinder outdoor learning processes. For instance, a schoolyard built of concrete or one where cars are allowed to park is an unsafe environment for children to engage in outdoor activities. Similarly, the lack of equipment for educational purposes and play limits the extent to which teachers utilize schoolyards. If schoolyards are not designed with children in mind, it becomes difficult for educators to envision and execute meaningful outdoor activities with the children in their care.

\subsection{Filling the Gaps and Creating Opportunities for Outdoor Play in Greece}

A number of changes need to be made to outdoor kindergarten environments to ensure that children benefit from their early involvement in activities outside the classroom. It is essential that young children have frequent and regular opportunities to explore and learn in the outdoors. This should not be considered an optional extra; rather educational organizations should emphasize the importance and value of daily outdoor experiences for learning and 
development. Unfortunately, there has been a cultural shift in Greek society in recent years that has reduced children's access to and use of outdoor spaces. Contributing factors include parents' increased fear for their children's safety and technological advances, such as television, and video and computer games, that have led to the prominence of sedentary indoor activities among children.

In light of these shortcomings and challenges, policy makers and educational institutions should consider the following proposals to improve children's opportunities to move beyond their immediate indoor environments:

- Enrich the national kindergarten curriculum with outdoor activities and outside lifestyles. Children should be given more time to engage in outdoor activities. However, time alone is not enough to improve the outcomes of outdoor activities. Teacher training, reduced intervals between outdoor play, and enhanced outdoor environments can all make a significant contribution to supporting children's physical and cognitive processes. Razak et al. (2018) suggest that multiple periods of outdoor play increase the rate at which children are exposed to "moderate-to-vigorous physical activity." Tandon et al. (2019) recommend that children have 60-90 minutes of outdoor play per day. Sixty minutes of playtime per day leads to more energetic play (Driediger et al., 2018). Tucker et al. (2017) have found a strong relationship between outdoor playtime and children's physical activity. Therefore, time and other factors are crucial to improving outdoor activities. Based on the current evidence, 60-90 minutes should be allocated as the standard time for outdoor activities for kindergarten children.

- Augment the curricula of university Early Child Education departments to include the concept of outdoor education. Many methods can be employed to engage kindergarten children in outdoor activities. Trainee teachers can be taught such approaches as play, storytelling, the use of outdoor pavement chalk and unstructured materials. Similarly, different spaces, including schoolyards, forests and parks, can be utilized as environments where outdoor activities are taught. Teachers can use play to facilitate children's outdoor activities, and to interact with nature and natural materials either freely or under guided conditions. Teachers may choose to guide play or allow children to direct their own engagements with nature. Guided play is appropriate in instances where the teacher feels that the environment poses some form of risk. Therefore, with the support of the teacher, children can participate in games that help them to connect with nature. Stories can help children to connect history with current world events. Children can benefit from stories during outdoor activities as they seek to understand the outside environment (Davies, 2020). When children are told stories, they connect those stories to the surrounding environment and the characteristic features of that environment. Davidson (2018) suggests that during outdoor activities such as museum visits, adults should encourage children to ask questions. These questions provide the adults with guidance as to the type of stories that will help children to gain better understanding of the topic at hand. As Davidson (2018) notes, some questions may have immediate answers, while others might require time to be thought about and answered, and still others may have no answer at all. Therefore, teachers are encouraged to embrace storytelling to improve their interactions with preschool children and to support children in their developing understanding of the environment and its components. 
- Create local authority public outdoor play areas and open-air leisure activities in urban areas. It is important to address the dissenting voices regarding outdoor activities for children. Parents' concerns for their children are genuine as they fear injury and illness. However, it is essential that parents learn that the benefits of outdoor play outweigh the risks. In addition, the environment in which outdoor activities occur enhances children's engagement in those activities. In parks, for instance, children can indulge their curiosity to explore their surroundings and seek clarification regarding what they do not understand, while in forests they can play with soil and other natural materials under the guidance of the teacher. Unstructured materials include leaves, sticks and rocks and other objects that children are exposed to in outside environments (Cordiano et al., 2019). These open-ended materials provide children with opportunities to be creative. Imagination is an important part of play as it helps children to brainstorm on the appropriate use of the available materials. As a result, children's creativity and problem-solving skills are enhanced as they engage their brains to think of games or other activities based on the materials to hand.

- Inform parents of the benefit of acquainting children with the natural environment and encouraging lifelong engagement in nature-based motor activities. Preschools can be at the forefront of ensuring that parents, educators and other stakeholders are supportive of outside activities. Institutions can organize programmes to educate parents about schoolyard activities. For instance, through schoolyard play, even very young children can make effective use of their sensory organs to development new concepts. Helping parents to understand the benefits of outdoor play is crucial to adjusting their perceptions of their children's involvement in such activities.

- Install better schoolyard equipment and create more suitable outdoor play spaces to avoid injuries. Preschool environments should promote effective and healthy educational activities. Schoolyards and playgrounds can be structured in ways that align to the development of children's cognitive and motor skills. Playgrounds should include such facilities as sand pits, traffic training, and playground equipment. According to Coe (2020), equipment can either be portable or fixed. Fixed equipment might include slides, swings and play structures, while portable equipment might include toys, balls and gardening tools. Alphabet activities can also help preschool children to learn letter formation. This fun method allows children to form letters and find meaning from the letters. To increase the fun, buckets of water can be used by the children to splash water on the letters as they try to identify incomplete letters. This practice helps teachers to understand the visual capabilities of children in the course of play.

\section{Conclusion}

It is important to note that play in free and natural environments is an important determinant of the health and development of preschool children in the next stages of their lives. Therefore, all of the above-mentioned social stakeholders must successfully cooperate at a national level. Outdoor play in Greek kindergartens should be a continuation of indoor education, supporting children to live healthier physical, emotional, psychological and spiritual lives. 


\section{References}

Abd Rahim, S. N. F., Badzisb, M., \& Rahmanc, N. S. N. A. (2020). How do children experience nature at preschool? A preliminary study. Retrieved April 2, 2021, from https://www.qualitative-research-conference.com/download/proceedings-2020/240.pdf

Ashiabi, G.S. (2007). Play in the preschool classroom: Its socioemotional significance and the teacher's role in play. Early Childhood Education Journal, 35, 199-207. https://doi.org/10.1007/s10643-007-0165-8

Barnett, L. A. (1990). Developmental benefits of play for children. Journal of Leisure Research, 22(2), 138-153. https://doi.org/10.1080/00222216.1990.11969821

Bento, G., \& Dias, G. (2017). The importance of outdoor play for young children's healthy development. Porto Biomedical Journal, 2(5), 157-160. https://doi.org/10.1016/j.pbj.2017.03.003

Coe, D. P. (2020). Means of optimizing physical activity in the preschool environment. American Journal of Lifestyle Medicine, 14(1), 16-23. https://doi.org/10.1177/1559827618818419

Cordiano, T. S., Lee, A., Wilt, J., Elszasz, A., Damour, L. K., \& Russ, S. W. (2019). Nature-based education and kindergarten readiness: Nature-based and traditional preschoolers are equally prepared for kindergarten. International Journal of Early Childhood Environmental Education, 6(3), 18-36. https://files.eric.ed.gov/fulltext/EJ1225659.pdf

Davidson, C. (2018). The importance of taking children to museum. Retrieved March 12, 2021, from https://www.joseloffgallery.org/on-view

Davies, L. (2020). Storytelling and nature education. Retrieved February 25, 2021, from https://www.wildernessawareness.org/articles/storytelling-and-nature-education/

Doliopoulou, E., \& Rizou, C. (2012). Greek kindergarten teachers' and parents' views about changes in play since their own childhood, European Early Childhood Education Research Journal, 20(1), 133-147.

Driediger, M., Vanderloo, L. M., Truelove, S., Bruijns, B. A., \& Tucker, P. (2018). Encouraging kids to hop, skip, and jump: emphasizing the need for higher-intensity physical activity in childcare. Journal of Sport and Health Science, 7(3), 333-336. https://doi.org/10.1016/j.jshs.2018.03.003

Erdem, D. (2018). Kindergarten teachers' views about outdoor activities. Journal of Education and Learning, 7(3), 203-218. https://doi.org/10.5539/jel.v7n3p159

Flannigan, C., \& Dietze, B. (2017). Children, outdoor play, and loose parts. Journal of Childhood Studies, 42(4),
https:/journals.uvic.ca/index

https://journals.uvic.ca/index.php/jcs/article/download/18103/7616

Garitsis I., Kouthouris C., Zafeiroudi A., \& Alexandris. K. (2010). The effect of 'Green school yards' on environmental awareness, learning, physical, social and mental health of 
primary school students. Sports \& Recreation Management, 7(2), 19-37.

Gregoriadis, A., Tsigilis, N., Grammatikopoulos, V., \& Kouli, O. (2016). Comparing quality of childcare and kindergarten centres: the need for a strong and equal partnership in the Greek early childhood education system, Early Child Development and Care, 186(7), 1142-1151, https://doi.org/10.1080/03004430.2015.1077820

Guirguis, R. (2018). Should we let them play? Three key benefits of play to improve early child programs. International Journal of Education and Practice, 6(1), 43-49. https://doi.org/10.18488/journal.61.2018.61.43.49

Haga, M., Tortella, P., Asonitou, K., Charitou, S., Koutsouki, D., Fumagalli, G., \& Sigmundsson, H. (2018). Cross-cultural aspects: Exploring motor competence among 7-to 8-year-old children from Greece, Italy, and Norway. Sage Open, 8(2), 1-9. https://doi.org/10.1177/2158244018768381

Hargraves, V. (n.d.). How can I help children make the most out of outdoor play? https://theeducationhub.org.nz/how-can-i-help-children-make-the-most-out-of-outdoor-play/

Hu, H., Wu, T., Fan, L., Zuo, K., Chen, L., Zhang, J., \& Zhao, X. (2020). Knowledge of Child Health and Affecting Factors Among Preschool Teachers: A Cross-Sectional Study in Chongqing, China. Risk Management and Healthcare Policy, 13, 2515-2524. https://doi.org/10.2147/RMHP.S280214

Kalpogianni, D. E. (2019). Why are the children not outdoors? Factors supporting and hindering outdoor play in Greek public day-care centres. International Journal of Play, 8(2), 155-173. https://doi.org/10.1080/21594937.2019.1643979

Kokolaki, S., Kouli, O., Bebetsos, E., \& Goudas, M. (2018). Mothers' self-efficacy regarding dietary behaviour and physical activity of preschool children. International Journal of Pediatrics, 6(1), 6843-6850. https://doi.org/10.22038/ijp.2017.28512.2479

Little, H., \& Wyver, S. (2008). Outdoor play: Does avoiding the risks reduce the benefits? Australasian Journal of Early Childhood, 33(2), 33-40. https://doi.org/10.1177/183693910803300206

Loebach, J., \& Cox, A. (2020). Tool for Observing Play Outdoors (TOPO): A New Typology for Capturing Children's Play Behaviours in Outdoor Environments. International Journal of Environmental Research and Public Health, 17(15), 5611, 1-34. https://doi.org/10.3390/ijerph17155611

Manwaring, B and Taylor, C (2006). The Benefits of Play and Playwork. Skills active, London. $\quad$ Retrieved June 15, 2021, from https://gwealantops.org/content/uploads/2018/03/benefits-of-play-and-playwork.pdf

O’Neill, S., Rajendran, K., \& Halperin, J. M. (2012). More than child's play: the potential benefits of play-based interventions for young children with ADHD. Expert Review of Neurotherapeutics, 12(10), 1165-1167. https://doi.org/10.1586/ern.12.106 


\section{Mll Macrothink}

Journal of Studies in Education

ISSN 2162-6952

2021, Vol. 11, No. 3

Palmer, K. K., Chinn, K. M., \& Robinson, L. E. (2019). The effect of the CHAMP intervention on fundamental motor skills and outdoor physical activity in preschoolers. Journal of Sport and Health Science, 8(2), 98-105. https://doi.org/10.1016/j.jshs.2018.12.003

Perlman, M., Howe, N., \& Bergeron, C. (2020). How and why did outdoor play become a central focus of Scottish early learning and care policy? Canadian Journal of Environmental Education (CJEE), 23(2), 46-66. https://cjee.lakeheadu.ca/article/viewFile/1618/978

Pomohaci, M., \& Sopa, I. S. (2017). Extracurricular sport activities and their importance in children socialization and integration process. Scientific Bulletin-Nicolae Balcescu Land Forces Academy, 22(1), 46-59.

Razak, L. A., Yoong, S. L., Wiggers, J., Morgan, P. J., Jones, J., Finch, M., ... \& Wolfenden, L. (2018). Impact of scheduling multiple outdoor free-play periods in childcare on child moderate-to-vigorous physical activity: a cluster randomized trial. International Journal of Behavioral Nutrition and Physical Activity, 15(1), 1-12. https://ijbnpa.biomedcentral.com/articles/10.1186/s12966-018-0665-5

Rodriguez-Ayllon, M., Cadenas-Sánchez, C., Estévez-López, F., Muñoz, N. E., Mora-Gonzalez, J., Migueles, J. H., ... \& Esteban-Cornejo, I. (2019). Role of physical activity and sedentary behaviour in the mental health of preschoolers, children and adolescents: a systematic review and meta-analysis. Sports Medicine, 49(9), 1383-1410. https://doi.org/10.1007/s40279-019-01099-5

Sakellariou, M., \& Banou, M. (2020). Play within outdoor preschool learning environments of Greece: a comparative study on current and prospective Kindergarten Educators. Early Child Development and Care, 1-17. https://doi.org/10.1080/03004430.2020.1813123

Sando, O. J. (2019). The outdoor environment and children's health: a multilevel approach. International Journal of Play, 8(1), 39-52. https://doi.org/10.1080/21594937.2019.1580336

Sando, O. J., \& Sandseter, E. B. H. (2020). Affordances for physical activity and well-being in the ECEC outdoor environment. Journal of Environmental Psychology, 69, 101430, 1-8. https://doi.org/10.1016/j.jenvp.2020.101430

Sandseter, E. B. H., Cordovil, R., Hagen, T. L., \& Lopes, F. (2020). Barriers for Outdoor Play in Early Childhood Education and Care (ECEC) Institutions: Perception of Risk in Children's Play among European Parents and ECEC Practitioners. Child Care in Practice, 26(2), 111-129. https://doi.org/10.1080/13575279.2019.1685461

Saridi, M., Toska, A., Latsou, D., Karakousi, S., Albani, E., Souliotis, K., \& Sarafis, P. (2021). The effect of physical activity and indoor environment on preschool children's health. Magna Scientia Advanced Research and Reviews, 1(2), 045-055. https://doi.org/10.30574/msarr.2021.1.2.0011

Slining, M., Wills, S., Fair, M., Stephenson, J., Knobel, S., Pearson, M., ... \& Negrete, M. (2021). LiveWell in early childhood: results from a two-year pilot intervention to improve nutrition and physical activity policies, systems and environments among early childhood 
education programs in South Carolina. BMC Public Health, 21(1), 1-9. https://bmcpublichealth.biomedcentral.com/articles/10.1186/s12889-021-10975-7

Tandon, P. S., Downing, K. L., Saelens, B. E., \& Christakis, D. A. (2019). Two approaches to increase physical activity for preschool children in child care centres: A matched-pair cluster-randomized trial. International Journal of Environmental Research and Public Health, 16(20), 4020, 1-11. https://doi.org/10.3390/ijerph16204020

Tandon, P. S., Saelens, B. E., Zhou, C., \& Christakis, D. A. (2018). A comparison of pre-schoolers' physical activity indoors versus outdoors at child care. International journal of environmental Research and Public Health, 15(11), 2463, 1-7. https://doi.org/10.3390/ijerph15112463

Tucker, P., Vanderloo, L. M., Johnson, A. M., Burke, S. M., Irwin, J. D., Gaston, A., ... \& Timmons, B. W. (2017). Impact of the Supporting Physical Activity in the Childcare Environment (SPACE) intervention on pre-schoolers' physical activity levels and sedentary time: a single-blind cluster randomized controlled trial. International Journal of Behavioral Nutrition and Physical Activity, 1-11. https://ijbnpa.biomedcentral.com/articles/10.1186/s12966-017-0579-7

Tuuling, L., Õun, T., \& Ugaste, A. (2019). Teachers' opinions on utilizing outdoor learning in the preschools of Estonia. Journal of Adventure Education and Outdoor Learning, 19(4), 358-370. https://doi.org/10.1080/14729679.2018.1553722

Venetsanou F., \& Kambas, A. (2017). Physical activity promotion in Greek preschools: The gap between theory and practice. Early Childhood Education Journal, 45, 437-444. https://doi.org/10.1007/s10643-016-0788-8

Venetsanou, F, Kambas, A., Gourgoulis, V., \& Yannakoulia, M. (2019). Physical activity in pre-school children: Trends over time and associations with body mass index and screen time, Annals of Human Biology, 46(5), 393-399. https://doi.org/10.1080/03014460.2019.1659414

Wray, A., Martin, G., Ostermeier, E., Medeiros, A., Little, M., Reilly, K., \& Gilliland, J. (2020). Evidence synthesis-Physical activity and social connectedness interventions in outdoor spaces among children and youth: a rapid review. Health Promotion and Chronic Disease Prevention in Canada: Research, Policy and Practice, 40(4), 104. https://www.ncbi.nlm.nih.gov/pmc/articles/PMC7197641/

Zafeiroudi, A. (2014). Physical Education \& Environmental Education: The Influence of an Outdoor Activities Program on Environmental Responsibility. Inquiries in Sport \& Physical Education, 11(3), 22-35.

Zafeiroudi, A. (2020). Enhancing adolescents' environmental responsibility through outdoor recreation activities, Academic Journal of Interdisciplinary Studies, 9(6), 43-55. https://doi.org/10.36941/ajis-2020-0110

Zafeiroudi, A., \& Hatzigeorgiadis, A. (2014). Validation of the Greek version of the responsible environmental behaviour scale and relationships with participation in outdoor 


\section{Macrothink}

Journal of Studies in Education

ISSN 2162-6952

activities. International Journal of Sport Management, Recreation \& Tourism, 13, 30-37.

Zaragas, H. K. \& Pliogou, V. (2020) Assessment and pedagogical implications of young children's psychomotor development in Greek kindergarten schools, Education 3-13, 48(2), 239-251. https://doi.org/10.1080/03004279.2019.1684540

\section{Copyrights}

Copyright for this article is retained by the author(s), with first publication rights granted to the journal.

This is an open-access article distributed under the terms and conditions of the Creative Commons Attribution license (http://creativecommons.org/licenses/by/4.0/) 